\title{
Premarital sexual behaviour among unmarried college students of Gujarat, India
}

Rachna Sujay

Follow this and additional works at: https://knowledgecommons.popcouncil.org/departments_sbsr-rh

Part of the Demography, Population, and Ecology Commons, Family, Life Course, and Society Commons, and the International Public Health Commons How does access to this work benefit you? Let us know!

\section{Recommended Citation}

Sujay, Rachna. 2009. "Premarital sexual behaviour among unmarried college students of Gujarat, India," Health and Population Innovation Fellowship Programme Working Paper no. 9. New Delhi: Population Council. 
This report is the result of a project entitled "Youth Culture: Sexual Norms and Behaviours of College Going Youth in Gujarat," undertaken as part of the Health and Population Innovation Fellowship (HPIF) awarded to the author in 2005.

The HPIF programme is administered by the Population Council, New Delhi and is a continuation of the MacArthur Foundation's Fund for Leadership Development (FLD) fellowship programme that continued over the period 1995 to 2004. The Council is grateful to the MacArthur Foundation for its support to this programme.

The HPIF programme aims to support mid-career individuals who have innovative ideas, leadership potential, and the capacity to help shape policy and public debate in the field of population, reproductive health and rights in general, with a focus on two priority themes maternal mortality and morbidity, and the sexual and reproductive health and rights of young people. Since the transfer of the programme to the Population Council through 2006, a total of 17 individuals have been supported under the HPIF programme.

For additional copies of this report, please contact:

Rachna Sujay

C/o Sujay Ojha

Quarter No. C -9

National Dairy Development

Board Campus

Anand, Gujarat 388 001, India

Email : rachnasujay@gmail.com
Population Council

Zone 5A, Ground Floor

India Habitat Centre

Lodi Road, New Delhi 110003

Phone: 011-24642901/02

Email: info-india@popcouncil.org

Web site: http://www.popcouncil.org/asia/india.html

The Population Council is an international, non-profit, non-governmental organisation that seeks to improve the well-being and reproductive health of current and future generations around the world and to help achieve a humane, equitable and sustainable balance between people and resources. The Council conducts biomedical, social science and public health research, and helps build research capacities in developing countries.

Copyright $\odot 2009$ Rachna Sujay

About the author: Rachna Sujay has a Masters degree in Foods and Nutrition from M. S. University of Baroda (India). She has worked since 1995 in project development, implementation and evaluation in areas relating to public health and sexual and reproductive health more specifically.

Suggested citation: R. Sujay. 2009. “Premarital Sexual Behaviour among Unmarried College Students of Gujarat, India," Health and Population Innovation Fellowship Programme Working Paper, No 9. New Delhi: Population Council.

\section{(P) Population Council}




\section{Premarital Sexual Behaviour among Unmarried College Students of Gujarat, India}

Rachna Sujay

Fellow

Health and Population Innovation Fellowship Programme 


\section{Contents}

Introduction 1

Background 2

Study design 4

Analysis 7

Profile of study participants 8

College life and opportunities for, and attitudes on developing intimate relationships 10

Daily life 10

Student-negotiation skills 11

Attitudes towards pre-marital relationships 12

Awareness about sexual and reproductive matters 16

Awareness of sexual and reproductive health matters 17

School and college-based sex education 18

Student perceptions about the need for sex education 18

Interaction with parents and peers 19

Parental interaction, attitudes and control 19

Interaction and communication with peers 22

Opposite-sex romantic and sexual relations 25

Romantic and sexual relation 25

Risky sexual behaviour 26

Factors associated with pre-marital sex and consistent condom use 30

Unintended pregnancy and abortion 34

Summing up and recommendations

Summing up

Limitations 38

Recommendations 39

References 41 


\section{List of Tables}

Table 2.1: Socio-demographic profile, Gujarat 3

Table 2.2: Distribution of selected classes and study participants, by faculty and year of study 6

Table 3.1: Socio-demographic profile of unmarried college students 8

Table 4.1: Profile of student life 10

Table 4.2: Perceptions of own skill in negotiating various outcomes 12

Table 4.3: Self-assessment regarding upholding traditional norms 12

Table 4.4: Student attitudes about romantic and sexual relationships

Table 5.1: Reproductive and sexual health awareness 16

Table 6.1: Parent-child relationships: communication, parental attitudes and socialisation patterns

Table 6.2: Parents versus peers as confidantes on relationship matters and personal problems

Table 6.3: Peer interaction and pressure experienced by unmarried college students in Gujarat

Table 7.1: Pre-marital romantic relations and physical intimacy including sex within romantic relationships

Table 7.2: Risky pre-marital sex behaviour among sexually experienced unmarried college students in Gujarat, stratified by gender 27

Table 7.3 Odd ratios from logistic regression analyses assessing the likelihood that students had ever experienced physical intimacy, sexual relations and that sexually experienced students had practised consistent condom use, by selected characteristics 32-33

Table 8.1: Unintended pregnancy experiences reported by sexually experienced male and female students 34

IV $\mid$ Rachna Sujay 


\section{Introduction}

In India more than 13 million youth, representing 7 percent of the population aged 15-24, are pursuing a college education (12.9 million in 2001, RGI, 2001a). For most of these youth, college represents a shift towards greater independence from home and school settings, an opportunity to form new friendships, and for several, an opportunity to experience romantic and/or sexual relationships. Studies focusing on sexual experiences amongst college-going youth in India are relatively rare, and estimates derived from these vary widely: a study among low-income college students in Mumbai revealed that 26 percent and 3 percent of male and female students, respectively, were sexually experienced (Abraham and Kumar, 1999). Another report showed that 18 percent of male university students in Gujarat were sexually experienced (Gujarat Behavioural Surveillance Survey, 2000), a third conducted in two university settings in Delhi revealed that 39 percent of male student and 20 percent of young women had engaged in pre-marital sex (Sachdev, 1998) and a fourth, among adolescents in classes 9 and 11 in Patna suggests that 10 percent and 1 percent of male and female students, respectively, had engaged in sexual relations (Shekhar et al., 2007). Little is known, however, about the role that family-, peer-, college- and individual-level factors play in determining whether or not youth engage in pre-marital sex, and more importantly, the extent to which such sexual experiences are wanted and practiced in a safe manner. As a result, knowledge about the special sexual health programme needs, and the design of health services for college and university students is scarce.

The aim of this report is to fill this gap, and specifically to explore experiences of sexual relations and factors (including, for example, those at the individual, parental, peer and college levels) associated with pre-marital sex, safe and otherwise, among college-going male student and women in Gujarat. Findings are intended to inform the design and delivery of sexual health programmes catering to the young in colleges and universities in India. 


\section{Background}

Available studies on pre-marital sexual experience among young people conducted in India are generally small, using variable methodologies and focusing on young people of different ages (Abraham and Kumar, 1999; Alexander et al., 2006; Awasthi and Pande, 1998; Jejeebhoy, 2000; Mehra, Savithri and Coutinho, 2002; Patel and Andrew, 2001; Shekhar et al., 2007). Although, as a result, findings cannot be generalised, there is considerable consistency in findings. They suggest that between 15 percent and 30 percent of young men, and fewer than 10 percent of young women reported the experience of penetrative sex, and that substantially more report a romantic relationship or other forms of physical intimacy, including holding hands, kissing or touching private parts (Alexander et al., 2006). For example, a community-based study of youth aged 15-24 in Pune district, Maharashtra, reports that amongst young men, 17-24 percent had had a romantic relationship, 20-26 percent had engaged in some form of physical intimacy and 16-18 percent had had sex; the proportions among young women were 5-8 percent, 4-6 percent and 1-2 percent, respectively (Alexander et al., 2006). A community-based study of young adults aged 18-35 in Orissa reported that 22 percent of single men and 27 percent of married men had experienced pre-marital sex (Collumbien et al., 2008), and likewise, in a qualitative study in a Delhi slum, several unmarried adolescents aged 13-19 years had reported some kind of sexual experience (Sodhi et al., 2008).

Most studies have been descriptive and few have focused on the correlates of sexual behaviour. There are, however, exceptions. A study of sexual experience among 966 low-income college-going students in Mumbai (Abraham and Kumar, 1999) noted that the sexually experienced were significantly more likely than others to differ on individual characteristics: for example they were more likely to have access to resources, hold positive attitudes towards pre-marital sex, report more social interaction with peers and be exposed to pornographic materials. Factors such as parental restrictiveness, family religiosity and income, played no role in influencing whether or not these students had experienced sex. In another study conducted amongst adolescents in a slum setting in Pune city and the surrounding rural areas, the level of self-confidence and peer interaction were significantly associated with reports of experiences of romantic and sexual relations; here while parental restrictiveness was not associated with either set of relations, the extent to which youth reported close interaction with parents was inversely associated with these experiences (Alexander et al., 2007). Finally, a study of adolescents in a Delhi slum setting, using entirely qualitative methods, reports, similarly, that parental restrictiveness does not deter young people from forming romantic partnerships or engaging in sexual relations (Mehra, Savithri and Coutinho, 2002).

This study explores the situation of college-going youth in Gujarat. A socio-demographic profile of Gujarat (Table 2.1) highlights that the population is considerably better off than is the population of India in general. For example, 60 percent of the population of Gujarat resides in the topmost two wealth quintiles, compared to 40 percent in India more generally. Likewise, almost 9 in 10 homes reported electricity, compared to 
two-thirds of those in India more generally; and two-thirds of the population resided in pucca houses compared to fewer than half of those in India more generally.

As far as social indicators are concerned, differences are not as consistent. Marriage age for young women was indeed considerably higher in Gujarat than in India in general, with 35 percent of those aged 18-29 married before they were 18 in Gujarat, compared to 46 percent in India more generally. In contrast, on several other social indicators, and particularly on those pertaining to youth, differences were not as wide. For example, literacy rates are just slightly higher in Gujarat than in India more generally. Mass media exposure was reported by just slightly more young people in Gujarat than in India more generally and awareness of HIV/AIDS was somewhat lower among youth in Gujarat than those in India more generally. And as in India more generally, in Gujarat, some 6 percent of young men and 4 percent of young women aged 15-24 were pursuing their education, compared to 8 percent and 5 percent, respectively, in India more generally.

Table 2.1:

Socio-demographic profile, Gujarat

\begin{tabular}{|c|c|c|}
\hline Demographic Indicators & India & Gujarat \\
\hline Total Population (in millions) ${ }^{1}$ & 1028.6 & 50.7 \\
\hline Population aged $15-24^{1}(\%)$ & 18.5 & 19.8 \\
\hline Population Sex Ratio ${ }^{1}$ & 933.0 & 920.0 \\
\hline Total fertility rate ${ }^{2}$ & 2.68 & 2.42 \\
\hline Wealth status: \% households residing in top 2 quintiles ${ }^{2}$ & 40.0 & 60.0 \\
\hline Household amenities: \% households with electricity² & 67.9 & 89.3 \\
\hline Residence in a pucca house ${ }^{2}(\%)$ & 45.9 & 67.3 \\
\hline Literacy rate (male) ${ }^{1}(\%)$ & 75.3 & 79.7 \\
\hline Literacy rate (female) ${ }^{1}(\%)$ & 53.7 & 57.8 \\
\hline \multicolumn{3}{|l|}{ Mass media exposure among youth (15-24) ${ }^{2}$} \\
\hline Males (\%) & 88.0 & 90.2 \\
\hline Females (\%) & 70.2 & 76.2 \\
\hline \multicolumn{3}{|l|}{ Youth aged $15-24$ pursuing college education (\%) ${ }^{1}$} \\
\hline Males (\%) & 8.2 & 5.8 \\
\hline Females (\%) & 5.3 & 4.3 \\
\hline Women aged $18-29$ first married at $18^{2}(\%)$ & 45.6 & 35.4 \\
\hline Men aged $21-29$ first married at $21^{2}(\%)$ & 26.6 & 26.8 \\
\hline \multicolumn{3}{|l|}{ Youth aged 15-24 who have heard of HIV-AIDS² (\%) } \\
\hline Males (\%) & 88.0 & 85.6 \\
\hline Females (\%) & 74.7 & 57.0 \\
\hline
\end{tabular}

Source: ${ }^{1}$ Office of Registrar General of India, 2001a; 2001b; ${ }^{2}$ IIPS and Macro international 2007 
There are 828 colleges in Gujarat, located in 15 universities, with an estimated strength of 6,65,000 students (University Grants Commission, nd). The three selected university settings—Gujarat University (Ahmedabad), Maharaja Sayajirao University (Vadodara) and Sardar Patel University (Vallabh Vidyanagar, Anand)—are among the largest of all universities situated in Gujarat, and more than two in five university students in the state are enrolled here. By far, the largest university is Gujarat University, in which approximately 2,25,000 students are enrolled (www.gujaratuniversity.org, accessed 2009). The remaining two universities are relatively smaller: about 35,000 are enrolled in Maharaja Sayajirao University (www.msubaroda.ac.in, 2009), and about 27,000 are enrolled in Sardar Patel University (www.spuvvn.edu, 2009).

College life is characterised, for many students, by more independence and opportunities for social mixing than before. Classes are mixed, as are such programmes as National Student Service (NSS) camps, offering male and female students the opportunity to interact. Many students, moreover, have begun to reside independently, that is, in hostels and private accommodations away from their families; others who continue to reside with their families may be less supervised by parents than when they were in school. Moreover, college life is characterised by celebrations of different kinds-'ribbon day', 'friendship day', 'chocolate day', 'traditional day', 'rose day' and so on-that provide opportunities for mixing between the sexes (see for example, Abraham, 2002). In Gujarat, social mixing amongst the youth is widespread at the time of the festival of 'Navratri', celebrated over nine days (nights) during which young men and women participate in 'Garba' sessions (folk dance of Gujarat) - this often continues throughout the night and is anecdotally associated with the development of romantic relationships among youth. In short, college-going youth—both men and women—have many opportunities to initiate or sustain romantic and sexual relationships.

\section{Study design}

The study was conducted during September 2005-September 2006 and involved both a qualitative phase as well as a survey of college students in three University settings: Gujarat University (Ahmedabad), Maharaja Sayajirao (MS) University (Vadodara) and Sardar Patel (SP) University (Vallabh Vidyanagar, Anand). The qualitative phase was undertaken at two points in time, prior to the initiation of the survey and parallel with the survey (2005-06).

The pre-survey qualitative phase was intended to better understand youth lifestyles and sexual behaviour, practices, terminologies, perceptions and experiences, in order to inform the design of the survey instrument. A total of 5 focus group discussions (2 with female students and 3 with male students) and 9 in-depth interviews (5 and 4, respectively) were conducted at this stage. In order to select students for these discussions and interviews, the researcher approached student leaders and professors and adopted an opportunistic and snowball sampling method.

In addition, while the survey phase was ongoing, a total of 5 focus group discussions were held ( 4 with female students and 1 with male students) to confirm preliminary findings. In addition, all survey respondents were asked to provide their contact details if 
willing to be interviewed in-depth; 13 willing students who had reported pre-marital sexual experience were randomly selected and in-depth interviews with them were held (7 female students and 6 male students).

A total of 26 key informant interviews were held, at various points during the study, with gate-keepers, including parents (8), teachers (4) and health care providers (14), including 7 gynaecologists, 2 STI specialists and 5 pharmacists. Sample selection procedures were opportunistic. For example, students who were identified but not selected for focus group discussions or in-depth interviews were asked to permit researchers to interview their parents, and interviews were held with consenting parents of those who agreed and provided contact details of their parents. College teachers in the three universities were approached randomly for interview. Health care providers were also selected through snowballing, with students identifying neighbourhood doctors and pharmacies, and consenting providers identifying others.

In addition, a large-scale cross-sectional survey was conducted that covered students attending the first, second and third year BA/B.Com/B.Sc courses and the first and second year MA/M.Com/M.Sc courses, respectively. The sample was selected through stratified two-stage random sampling with well-defined inclusion and exclusion criteria. In the first stage, a total of 27 arts, science and commerce colleges affiliated to the three selected universities were randomly selected. College principals were asked to select classes from each of the three mentioned faculties, as well as each year of study from both the undergraduate and graduate levels, for the survey. They were asked to give priority to classes in which the teacher was absent so that disturbance to regular classes was kept to a minimum, and to select classes containing approximately equal numbers of male and female students. At least one class from each faculty and year of study were to be included from among undergraduate and graduate levels, respectively, and all students who attended that class were to be invited to participate. A total of 94 classes were thus selected out of which a total of 3,173 students comprised the study sample. In each faculty, more female than male students had attended class on the day the survey was fielded, and discussions with teachers and students suggested that some male students were engaged in wage earning activities and did not attend classes regularly; and that more male than female students spent college hours outside the classroom, including in the college canteen. The distribution of selected classes and participants by faculty and year of study is presented in Table 2.2. 
Table 2.2:

Distribution of selected classes and study participants, by faculty and year of study

\begin{tabular}{|l|c|c|c|c|}
\hline & $\begin{array}{c}\text { No. of classes } \\
\text { selected }\end{array}$ & \multicolumn{3}{|c|}{ No. of study participants } \\
\hline & & Total & Female & Male \\
\hline Total & 94 & 3173 & 1808 & 1365 \\
\hline Faculty & & & & \\
\hline Arts & 31 & 1081 & 698 & 383 \\
Commerce & 29 & 1100 & 564 & 536 \\
\hline Sciences & 34 & 992 & 546 & 446 \\
\hline Year of study & & & & \\
First year undergraduate & 21 & 751 & 420 & 331 \\
Second year undergraduate & 20 & 694 & 371 & 323 \\
Third year undergraduate & 19 & 727 & 401 & 326 \\
First year post-graduate & 16 & 488 & 304 & 184 \\
Second year post-graduate & 18 & 513 & 312 & 201 \\
\hline
\end{tabular}

Self-administered, anonymous questionnaires were fielded among students in classroom settings, thereby offering them privacy and confidentiality while responding to queries relating to intimate behaviour. Sensitive questions were placed towards the end of the questionnaire. The survey instrument was informed by insights from the pre-survey qualitative phases as well as from instruments used by other studies assessing youth sexual experiences in India and elsewhere (Cleland, 2001; IIPS and Population Council, 2008; Mohammadi et al., 2006). Separate questionnaires were prepared for male and female students, with an identical set of questions. The questionnaire was developed in English, translated into Gujarati, and translated back into English. It was then pre-tested among 60 undergraduate and post-graduate students in two of the selected universities. The final questionnaire was printed in both English and Gujarati. There were no skips or filters in the questionnaire. The questionnaire was distributed by the researcher in a classroom setting. The researcher began by introducing the study, its purpose and content; she stressed that there were no right or wrong answers and went over the consent procedures with the students. Students were given the option to refuse to respond to the entire, or portions of, the questionnaire. The researcher remained in the classroom while the students filled in the questionnaire and encouraged students to seek clarifications for any issues/concerns or problems relating to terminology. Students were requested to spread out in the classroom so that privacy was ensured. They took approximately one hour to complete the survey and check their responses. 


\section{Analysis}

Independent sample t-tests and chi-square tests are used to describe youth experiences and assess the significance of differences in responses of male and female students.

Binary logistic regressions were used to identify individual, family and peer level factors that were significantly associated with pre-marital sexual activity amongst the youth. 


\section{Profile of study participants}

A total of 3,202 students took part in the survey. Married students (14 or $0.4 \%$ ) were excluded from the final sample. Another $15(0.4 \%)$ students refused to take part in the survey (lack of time $=12$, refused because of the nature and type of questions=3). Finally, we had a sample of 3,173 students-1,808 females (57\%) and 1,365 males (43\%).

Table 3.1 presents a profile of our sample. The large majority were Hindu (88-89\%). Parents of most students were well educated-although mothers, in comparison to fathers, were less likely to have had a university education. However, parents of female students tended to be better educated than those of male students, suggesting that college going females were considerably more likely than males to be selective of young women with educated parents. The sample was aged between 17 and 27 years with a median age of 20 years among both females and males. Differences between youth studying in the three universities were negligible in these respects.

Table 3.1:

Socio-demographic profile of unmarried college students by sex of the student and University

\begin{tabular}{|c|c|c|c|c|c|c|c|c|}
\hline & \multicolumn{4}{|c|}{ Female } & \multicolumn{4}{|c|}{ Male } \\
\hline & GU & SPU & MSU & Total & GU & SPU & MSU & Total \\
\hline Median age & 19.0 & 20.0 & 20.0 & 20.0 & 20.0 & 20.0 & 20.0 & 20.0 \\
\hline Religion: \% Hindu & 90.7 & 87.9 & 89.0 & 89.3 & 88.9 & 90.5 & 84.3 & 88.2 \\
\hline Parents' education (\%) & & & & & & & & \\
\hline Mother's education: university+ & 26.7 & 37.8 & 31.2 & 31.4 & 14.4 & 20.2 & 19.3 & 18.1 \\
\hline Father's education: university+ & 54.1 & 61.1 & 54.6 & 56.1 & 43.5 & 48.8 & 41.9 & 45.1 \\
\hline Faculty of study (\%) & & & & & & & & \\
\hline Commerce & 29.0 & 31.6 & 32.7 & 31.2 & 34.7 & 30.4 & 56.4 & 39.3 \\
\hline Arts & 42.8 & 32.9 & 38.8 & 38.6 & 31.3 & 33.2 & 17.5 & 28.1 \\
\hline Science & 28.2 & 35.5 & 28.5 & 30.2 & 34.0 & 36.4 & 26.1 & 32.7 \\
\hline Course of study (\%) & & & & & & & & \\
\hline First year undergraduate & 27.7 & 23.4 & 19.4 & 23.2 & 28.2 & 21.9 & 23.1 & 24.2 \\
\hline Second year undergraduate & 20.7 & 23.1 & 18.7 & 20.5 & 23.6 & 25.2 & 21.6 & 23.7 \\
\hline Third year undergraduate & 23.3 & 18.0 & 23.9 & 22.2 & 23.1 & 24.5 & 23.9 & 23.9 \\
\hline First year post-graduate & 13.8 & 17.4 & 19.0 & 16.8 & 11.3 & 14.3 & 14.7 & 13.5 \\
\hline Second year post-graduate & 14.6 & 18.0 & 19.0 & 17.3 & 13.7 & 14.1 & 16.8 & 14.7 \\
\hline Number of students & 610 & 471 & 727 & 1808 & 432 & 539 & 394 & 1365 \\
\hline
\end{tabular}

Note: GU=Gujarat University; SPU=Sardar Patel University; MSU=Maharaja Sayaji Rao University

8 Rachna Sujay 
The proportion of male and female students in each faculty varied somewhat, with more males than females studying in the commerce stream, and more females than males in the arts stream. In addition, females constituted a larger percentage of the student body of Gujarat University and MS University than of SP University. Among male students, moreover, more than half of the students in MS University were studying commerce. Distributions by academic year, per college, were fairly similar; however, the sample contained a somewhat larger proportion of female than male students who were pursuing postgraduate studies (34\% and $28 \%$, respectively).

In the remaining sections of this report, we will discuss the situation of female and male students, irrespective of the university to which they belonged. Significant differences, wherever observed, are however, noted. 


\section{College life and opportunities for, and attitudes on developing intimate relationships}

As mentioned earlier, college life marks a significant transition towards adulthood for youth in terms of independence from the supervision of family and school authorities, exposure to new ideas; and opportunities to mix with a wider array of individuals, including those from the opposite sex. In this chapter, we explore aspects of the lives of college-going students in Gujarat.

\section{Daily life}

As Table 4.1 shows, the majority of students resided with parents or other relatives, however, 36 percent of male students and 17 percent of female students resided on their own, in hostels, paying guest accommodations, or other independent living arrangements. Living arrangements did, however, differ considerably, with more students in SP

Table 4.1:

Profile of student life

\begin{tabular}{|c|c|c|}
\hline & $\begin{array}{c}\text { Female } \\
(\mathrm{N}=1808)\end{array}$ & $\begin{array}{c}\text { Male } \\
(\mathrm{N}=1365)\end{array}$ \\
\hline \multicolumn{3}{|l|}{ Living arrangements(\%) } \\
\hline Resided with family or relatives & 83.4 & 64.2 \\
\hline $\begin{array}{l}\text { Resided independently (hostel/paying } \\
\text { guest/own accommodation) }\end{array}$ & 16.6 & 35.8 \\
\hline \multicolumn{3}{|l|}{ Source of money(\%) } \\
\hline Parents & 92.1 & 87.6 \\
\hline Job/work & 7.4 & 11.6 \\
\hline Other sources & 0.5 & 0.7 \\
\hline \multicolumn{3}{|c|}{ College related attendance and performance $(\%)$} \\
\hline Attended most/all classes & 86.8 & 73.1 \\
\hline Performed well in college* & 73.8 & 69.0 \\
\hline \multicolumn{3}{|l|}{ Exposure to pornographic films: (\%) } \\
\hline Ever watched blue films** & 12.2 & 71.4 \\
\hline \multicolumn{3}{|l|}{ Cigarette and alcohol consumption(\%) } \\
\hline Ever smoked cigarettes** & 0.9 & 23.4 \\
\hline Ever consumed alcohol** & 2.4 & 14.2 \\
\hline
\end{tabular}

Note: Gender differences of self statistically significant, ${ }^{*} p<0.01,{ }^{* *} p<0.001$

10 Rachna Sujay 
University, Anand, residing independently than those in Gujarat or MS Universities (not shown in tabular form). The majority reported that they were supported entirely by their parents, although 12 percent of male students and 7 percent of female students supported themselves through their own earnings, combining college with work. The majority of students reported, moreover, that they attended classes regularlyconsiderably more female students than male students, (87\% versus $73 \%$ ). Likewise, in response to a question on how they perceived their academic performance, more females than male students (74\% and $69 \%$, respectively) reported that they had performed well in their studies.

Students were also asked about their exposure to blue (pornographic) films, a leisure-time activity acknowledged in pre-survey focus group discussions, and their consumption of cigarettes and alcohol. Findings suggest that exposure to blue films was not unknown but that gender differences in viewership were wide: almost three in four male students (71\%) compared to just one in eight (12\%) female students reported exposure to blue films. As far as cigarette and alcohol consumption were concerned, few female students (1-2\%) reported that they engaged in these practices. Considerably more male students reported doing so: 23 percent reported smoking cigarettes and 14 percent reported alcohol consumption.

\section{Student-negotiation skills}

Students were also asked about their level of confidence and negotiation skills in realising a number of wanted outcomes. As reported in Table 4.2, negotiation skills were moderate. Three-fifths of students-63 percent and 61 percent of females and males, respectivelywere confident about confronting a person who had offended them, and $68 \%$ and $61 \%$, respectively, were confident that they could confront their parents if they did not wish to marry someone selected by them.

Negotiating skills in obtaining information about contraception, or contraceptive supplies, were reported by fewer students. While female students were about as likely as, or slightly more likely than male students to express confidence in their ability to confront those who offended them, express their unwillingness to marry someone of their parents' choice and they were considerably less likely to report confidence in their ability to negotiate on contraceptive matters. Indeed, just 10 percent of the female students, compared to 18 percent male students, reported confidence about their ability to discuss contraception with adults or health worker. Even fewer, just 4 percent of female students and 14 percent of male students, reported confidence in their ability to procure contraceptives from a medical store. In several in-depth interviews, students, including female students expressed confidence in their ability to negotiate decisions relating to marriage. For example:

...I have told them [parents] that if they have a valid reason then I will listen to them but if they reject my boyfriend or the person I want to marry on the pretext of religion, caste or financial status I am not going to listen to their objection. (In-depth interview, postgraduate female student, SP University, age 22) 
Table 4.2:

Perceptions of own skill in negotiating various outcomes

\begin{tabular}{|c|c|c|}
\hline $\begin{array}{l}\text { Percent of students reporting confidence in ability to } \\
\text { negotiate the following: } 1\end{array}$ & $\begin{array}{l}\text { Female } \\
(\mathrm{N}=1808)\end{array}$ & $\begin{array}{c}\text { Male } \\
(\mathrm{N}=1365)\end{array}$ \\
\hline Confronting a person when offended & 63.30 & 60.80 \\
\hline $\begin{array}{l}\text { Saying 'No' to parents if s/he did not want to marry a } \\
\text { person of their choice** }\end{array}$ & 68.10 & 61.00 \\
\hline Discussing contraception with adults or health worker** & 10.60 & 17.70 \\
\hline Purchasing contraceptives from a medical store** & 4.30 & 13.80 \\
\hline Mean Index of perceived negotiation skills & 1.46 & 1.53 \\
\hline
\end{tabular}

Note: Gender differences statistically significant, ${ }^{*} p<0.01,{ }^{* *} p<0.001 .{ }^{1}$ very confident about ability to conduct each activity

An index of negotiation skills was constructed that summarised the responses to the four dichotomous questions relating to their perceived confidence about realising a number of wanted outcomes, assigning a score of 1 to each response suggesting perceived negotiation skills, and 0 if not. As such, the index ranged from 0 to 4 . Findings suggest that both female and male students reported confidence in their ability to negotiate on about 1.5 of the 4 issues, with male students revealing slightly higher levels of perceived negotiation skills than female students.

\section{Attitudes towards pre-marital relationships}

Students were asked a number of questions relating to their attitude with regard to premarital sex. Also probed was their self-perception about the extent to which they adhered to, or rejected traditional norms (In your views and behaviours, how traditional "do you consider yourself to be?”) Findings, presented in Table 4.3, suggest that the large majority—about four in five-reported that they had "somewhat" traditional attitudes, or that they completely rejected traditional norms.

\section{Table 4.3:}

Self-assessment regarding upholding traditional norms

\begin{tabular}{|l|c|c|}
\hline Percent of students reporting: & $\begin{array}{c}\text { Female } \\
(\mathbf{N}=\mathbf{1 8 0 8})\end{array}$ & $\begin{array}{c}\text { Male } \\
(\mathbf{N}=\mathbf{1 3 6 5})\end{array}$ \\
\hline Highly traditional attitude & 19.5 & 21.6 \\
Somewhat traditional attitudes & 77.5 & 72.3 \\
Not at all traditional & 3.0 & 6.1 \\
\hline
\end{tabular}


Students were questioned extensively about their attitudes towards premarital intimate and sexual relationships. As shown in Table 4.4, a set of seven statements pertaining to relationships, sex, and use of contraceptives were included in the questionnaire, and students were asked to record whether they disagreed, agreed or had no opinion about the statement under consideration (a three-point Likert scale). Findings suggest that attitudes were mixed. On the one hand, the majority of students found it acceptable for an unmarried boy to have a girlfriend (70\% females and $81 \%$ males) and an unmarried girl to have a boyfriend (67\% and $76 \%$, respectively). On the other hand, students were far less likely to approve of pre-marital physical intimacy or sex. For example, three in five male students, and over half of female students agreed that it was acceptable for unmarried boys and girls to kiss, but many fewer believed that pre-marital sex was acceptable. Gender double standards were especially evident among male students: while $70 \%$ believed that girls should remain virgins until marriage, only 53\% believed that boys should not have sex until marriage. At the same time, almost half of male students (47\%) believed that pre-marital sex was acceptable if the couple practised contraception. Female students' responses reflected more traditional attitudes towards pre-marital sex among both young men and women and their attitudes toward pre-marital sex among boys and girls were similar; just $15 \%$ believed that pre-marital sex was acceptable if contraception were practised.

\section{Table 4.4:}

Student attitudes about romantic and sexual relationships

\begin{tabular}{|l|c|c|}
\hline Percent agreeing with the following statements: & $\begin{array}{c}\text { Female } \\
\text { (N=1808) }\end{array}$ & $\begin{array}{c}\text { Male } \\
\text { (N=1365) }\end{array}$ \\
\hline Its all right for an unmarried boy to have a girl friend*** & 69.8 & 80.8 \\
\hline Its all right for an unmarried girl to have a boy friend*** & 66.9 & 75.6 \\
\hline Its wrong for unmarried boys and girls to kiss each other** & 45.9 & 40.6 \\
\hline A boy will not respect a girl who agrees to have sex with him & 36.4 & 38.2 \\
\hline $\begin{array}{l}\text { Its all right for boys and girls to have sex before marriage if } \\
\text { they use methods to prevent pregnancy*** }\end{array}$ & 15.0 & 46.8 \\
\hline Girls should remain virgins until they marry** & 75.3 & 70.2 \\
\hline Boys should not have sex before marriage*** & 79.8 & 53.4 \\
\hline
\end{tabular}

Note: Gender differences of self statistically significant, ${ }^{*} p<0.05,{ }^{* *} p<0.01,{ }^{* * *} p<0.001$ 
These views about the acceptability of pre-marital romantic, but not sexual, relationships were echoed in focus group discussions and in-depth interviews with students. For example:

If girls will not have boyfriends or if only boys have the right to have girlfriends, then from where will we get girlfriends? So there is nothing wrong in girls having boyfriends. In fact more and more girls should have boyfriends. (Focus group discussion, undergraduate male students, MS University)

We have not had sex yet as both of us feel that sex should happen only after marriage otherwise what new are we going to do after marriage? (In-depth interview, undergraduate female student, SP University, age 18)

In the in-depth interviews, both female and male students described their reasons for disapproving pre-marital sex. Double standards were evident with both female and male students noting that disclosure of pre-marital sex would affect a girl's chances of getting married and that male student would not accept a wife who was not a virgin. Notably, pre-marital sex among male student was more widely accepted and not a single female student reported that women would not accept a husband who had engaged in pre-marital sex. For example, in in-depth interviews, young women commented:

Girls still accept sexually experienced boys. Boys say that they will accept a non-virgin girl but they rarely do. As long as the relationship is for time pass, any girl will do for them but when it comes to taking the girl home to introduce her to the family, they want a clean girl, I mean a girl who has no tags of involvement with other boy(s). It's very difficult to hide your past so if a girl or boy really wants to inquire about the past sexual relationships of their partner they can easily do so through the network of their friends. (In-depth interview, undergraduate female student, SP University, age 20)

I can vouch for my statement that boys will not marry a non virgin. If they say they do not mind marrying a girl who has had premarital sex, they are telling lies. I am saying this from my personal experience. (In-depth interview, undergraduate female student, SP University, age 19)

Male students' responses were largely similar:

I have seen maximum break-ups happening after a couple got physical. A boy will rarely marry a girl who is sexually involved with him because she is not going to offer him anything new after marriage. (In-depth interview, undergraduate male student, MS University, age 19) 
If my girlfriend can sleep with me then she can sleep with some other boy as well. All of us boys think the same. I keep persuading my girlfriend for sex but she always says no to me and I really love this attitude of hers. Basically for this reason, I will make sure that I marry her. (In-depth interview, postgraduate male student, SP University, age 22)

We boys have a criterion that we will marry only a virgin. (Focus group discussion, undergraduate male students, MS University) 


\section{Awareness about sexual and reproductive matters}

Since 2001, the Gujarat State AIDS Control Society has been implementing the School Adolescence Education Programme for students of classes 9 and 11 in 838 schools in Ahmedabad, Anand and Baroda (Gujarat State AIDS Control Society, 2006). Students receive education on HIV-AIDS, family planning and life skills. Despite this programme, findings suggest that college students, many of whom would have been in classes 9 and 11 after the initiation of this programme, had not been exposed to school-based sex education and remained poorly informed about sexual and reproductive health matters. This chapter describes students' awareness of sexual and reproductive matters and their exposure to and assessment of sex education programmes (Table 5.1).

\section{Table 5.1:}

Reproductive and sexual health awareness

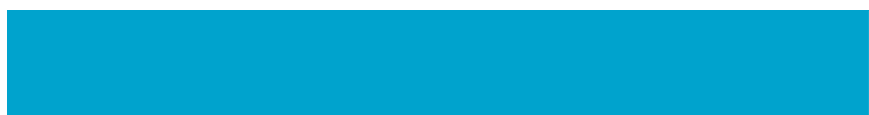

Awareness of sexual and reproductive matters (\%)

A woman can get pregnant the very first time she has sexual intercourse**

The condom is a suitable method of preventing pregnancy**

Oral pills are a method of preventing pregnancy**

Withdrawal can prevent pregnancy**

HIV/AIDS cannot be transmitted by kissing

Condoms can protect a person against HIV**

Mean index of awareness of sexual and reproductive matters**

\section{Experience of sex education (\%)}

Received sex/family planning education in school**

Received sex/family planning education in college ${ }^{* * *}$

Student perceptions about the need for sex education (\%)

Expressed interest in obtaining sex education at college*

Note: Gender differences statistically significant, ${ }^{*} p<0.01$, ${ }^{* *} p<0.001$ 


\section{Awareness of sexual and reproductive health matters}

In order to assess students' awareness of sexual and reproductive matters, a series of statements were posed, and they were asked to indicate whether the statement was true or false. The statements and students' responses are reported in Table 5.1. What is evident is that awareness was far from universal. For example, although most students rejected the common misconception that HIV can be transmitted by kissing, as many as 29 percent of female students and 17 percent of male students held this misconception. Similarly, while the majority of students were aware of the role condoms played in protecting against HIV, as many as one-quarter of female students were not aware of the protective role of condoms, as indicated in Table 5.1. Few students were aware, moreover, of the role of condoms, oral contraceptives and withdrawal in preventing pregnancy. Awareness was particularly limited about the fact that women can become pregnant the first time they have sex; indeed, just $14 \%$ of female students and $20 \%$ of male students reported awareness. A summary measure of sexual and reproductive health awareness that simply summed the number of correct responses made on the six items listed in Table 5.1, reiterates the extent to which awareness was limited: male students were correct about just 4 items, while female students were correct about just 3 .

In-depth interviews also show a lack of awareness and highlight the extent to which misconceptions existed among students, including those who were sexually experienced. For example:

I have heard that if a girl washes her vagina after intercourse, she will not get pregnant. (Focus group discussion, undergraduate male students, SP University)

I know she will not get pregnant because whenever I meet her, first I give her a pill of Mala D. I don't give her the entire packet because where will she keep it at home. I stay at the hostel so I have no problem of storage. I meet her for at least 10-15 times a month. My friends say that even if she took 10 tablets a month she will not get pregnant...and she has not got pregnant as yet. (In-depth interview, undergraduate male student, SP University, age 20)

I know of girls who are in physical relationships with their boyfriends for so many years now but still they have not got pregnant even once. My friends say, 'if her boyfriend ejaculates inside her once or twice she will not become pregnant'; 'If her boyfriend ejaculates inside and she stands up, she will not get pregnant'. I have also heard from my roommate that usually boys ejaculate out which does not result in pregnancy. That is why I allow my boyfriend to ejaculate outside of my body and do not force him to wear a condom. (In-depth interview, undergraduate female student, MS University, age 19)

Even among those aware of HIV-AIDS, misconceptions about modes of protection were evident. For example:

My current girlfriend is in class nine. All my previous girlfriends used to be of my age but since I have heard of AIDS, I got frightened. I have decided to have sex with only young girls, who are in class say seven or eight, of whom I can be sure that they 
have not been in any relationship previously. (In-depth interview, undergraduate male student, SP University, age 22)

\section{School- and college-based sex education}

As reported in Table 5.1, few students had received sex education in school: just 34-39 percent. In-depth interviews with those who had received sex education suggested that this was not comprehensive enough, and did not answer young people's queries about sexual and reproductive matters. For example:

All that was talked about at our college in the lecture on sex and relationship was that 'if you engage in sex, you will become pregnant'. I know that but tell me how I will not get pregnant, tell me how I cannot get STDs, what kind of STDs are there, tell me what happens if I get STDs, what are the symptoms, what are the names of these symptoms and if these are the names, then what happens in these STDs? This is all I want to know. (Focus group discussion, undergraduate female students, MS University)

At our college we once had a seminar on safe sex. The resource person said that safe sex is all about masturbation. I want to know more about masturbation. A guy is always taught to masturbate by somebody but a girl is never taught. So why aren't girls taught to masturbate? Is masturbation only for boys? (In-depth interview, undergraduate female student, MS University, age 18)

We had a lecture in our college but it was very lousy, I did not understand anything. ...so if the college wants to tell me about sex, tell me everything, all the terms that are used when a person talks about sex, tell me how it is done and what it involves. (In-depth interview, postgraduate female student, Gujarat University, age 20)

\section{Student perceptions about the need for sex education}

Given the lack of sex education in schools and the limited awareness of sexual and reproductive matters among students, including those who were sexually active, it is not surprising that students recognise the need for education that will enable them to engage in safe sexual relations. Indeed, as Table 5.1 shows, the overwhelming majority-about nine in ten students-reported a need for such education at the college level. 


\section{Interaction with parents and peers}

Interaction and communication with family and peers have been observed, in several studies, to be associated with whether or not youth engage in romantic and sexual relationships, and whether the sexual relations they experience are safe and wanted. Findings from research in other settings suggests that parent-youth interaction and communication tends to be somewhat limited, particularly in the area of sexual and reproductive matters; that the gap between norms held by parents and youth are wide; and socialisation patterns that strictly supervise actions of daughters do not necessarily limit the formation of romantic relationships among them (see, for example, Mehra et al., 2002; Alexander et al., 2006). Findings also suggest that peer influences can be both positive and negative. On the one hand, peers provide a social network and a supportive environment; in fact, for many it is this group that is the main source of information about sexual and reproductive matters. On the other hand, romantic and sexual relationships are often also the result of peer pressure (Bearman and Brückner, 1999; Kirby, 2001; Karim et al., 2003), and information provided by peers with regard to sexual and reproductive matters is often incomplete and inaccurate. In this chapter we explore respondents' interaction with their families on the one hand, and their peers, on the other.

\section{Parental interaction, attitudes and control}

As other studies have suggested, communication with parents was reported to be limited and perceived parental disapproval of boy-girl relationships was reported by many (see Table 6.1). Gender differences, moreover, were wide. As far as communication on contraceptive matters was concerned, just half of the female students (48\%) and even fewer male students (29\%) reported that they had obtained information from either their father or mother. Female students were considerably more likely to have obtained information from their mother compared to the father ( $47 \%$ and $10 \%$, respectively); gender differences were relatively mild for male students, with about one-fifth obtaining information from each parent (22\% from the mother; $20 \%$ from the father).

It was clear moreover that while small proportions of parents-21 percent and 15 percent of parents of young women and men, respectively-would disapprove of their college-going children having friends of the opposite sex, a considerably larger proportion was perceived to disapprove of their college-going children having a romantic relationship: 65 percent of parents of female students, and 37 percent of parents of male students. Likewise, the majority of students reported that their parents would play a critical role in determining whom they would marry-indeed, two-thirds of the female students and half of the male students reported that their parents would play the main role in selecting their spouse. Under such circumstances, it is unlikely that students were in a position to confide in their parents or seek their views on questions relating to relationships or marriage. 
Parental strictness with respondents was also explored. Questions probed perceptions about the extent of control their parents exercised regarding who the student's friends were, how he/she spent money, the kinds of clothes he/she wore, and how late he/she could stay out at night. Findings suggest that typically, parents of both male and female students were perceived to be strict; indeed, three-fifths or more, of female students and half or more of male students reported that their parents were strict about at least one of these four matters. A summary measure that sums the number of these four matters on which parents were perceived to be strict (factor analysis confirmed that these four indicators reflected a single factor) suggests that both male and female students perceived that parents were strict about 3 of the four issues discussed (2.84 and 2.85, respectively).

The quality of interaction with parents was measured by whether the student reported that his/her parents were very understanding and whether the parents had spent a lot of time with her/him. Findings show that while two-third of both male and female students reported that their parents were very understanding, more female than male students reported that their parents had spent a lot of time with them (55\% versus $41 \%$ ). A summary measure of the quality of parental interaction reflects whether or not both of these indicators of interaction were experienced; findings suggest that significantly more female than male students reported close interaction with parents on both these matters (43\% and 34\% among female and male students, respectively).

In the in-depth interviews, students underscored the fact that they preferred not to confide in their parents about romantic relationships with the opposite sex. For example:

I will never tell anyone about my girlfriend at home. Once I did, and had a hard time thereafter as my parents started treating her as a would-be daughter-in-law. Since then I never introduced my girlfriend to my parents. ... (In-depth interview, postgraduate male student, Gujarat University, age 20)

If ever I have a boyfriend I would first prefer to break the news to my friends because I feel very comfortable sharing my secrets with my friends. There is no inhibition at all when I talk to my friends. The second preference would be my elder sister and the last preference would be my mother because I hesitate to answer her questions as well as to counter question her. (In-depth interview, undergraduate female student, SP University, age 18) 


\section{Table 6.1:}

Parent-child relationships: communication, parental attitudes and socialisation patterns

\begin{tabular}{|c|c|c|}
\hline & $\begin{array}{l}\text { Female } \\
(\mathrm{N}=1808)\end{array}$ & $\begin{array}{c}\text { Male } \\
(\mathrm{N}=1365)\end{array}$ \\
\hline \multicolumn{3}{|l|}{$\begin{array}{l}\text { Communication with parents on reproductive health } \\
\text { matters }\end{array}$} \\
\hline \multicolumn{3}{|l|}{ Contraception information received from (\%) } \\
\hline Mother** & 46.8 & 22.1 \\
\hline Father** & 10.0 & 19.8 \\
\hline Either mother or father** & 47.8 & 28.5 \\
\hline \multicolumn{3}{|l|}{ Parental attitudes to opposite-sex interaction by respondent } \\
\hline \multicolumn{3}{|l|}{ Friendship with opposite sex classmates (\%)** } \\
\hline Would disapprove & 20.6 & 15.1 \\
\hline Would not disapprove & 59.8 & 62.2 \\
\hline Can’t say & 19.8 & 22.7 \\
\hline \multicolumn{3}{|l|}{ If student has a boy/girlfriend (\%)** } \\
\hline Would disapprove & 64.6 & 36.7 \\
\hline Would not disapprove & 8.6 & 29.3 \\
\hline Can’t say & 26.7 & 33.9 \\
\hline \multicolumn{3}{|l|}{$\begin{array}{l}\text { Parents' perceived influence on student's choice of } \\
\text { spouse }(\%)^{* *}\end{array}$} \\
\hline None & 5.5 & 12.3 \\
\hline Some & 27.9 & 38.5 \\
\hline A lot & 66.4 & 49.1 \\
\hline \multicolumn{3}{|l|}{ Socialisation experiences } \\
\hline \multicolumn{3}{|l|}{ Parental strictness } \\
\hline Parents are/were strict about selection of friends(\%)** & 62.0 & 69.6 \\
\hline Parents are/were vigilant about money spent by $\mathrm{R}(\%)^{* *}$ & 70.6 & 79.3 \\
\hline Parents are/were strict about the clothes $\mathrm{R}$ wears/wore(\%)** & 61.2 & 50.1 \\
\hline Parents are/were strict about $\mathrm{R}$ staying out late at night(\%)** & 91.4 & 85.0 \\
\hline $\begin{array}{l}\text { Parental strictness index ( } 0-4 \text {, mean number of items } \\
\text { about which parents are/were strict) })^{* *}\end{array}$ & 2.85 & 2.84 \\
\hline \multicolumn{3}{|l|}{ Parental interaction } \\
\hline Parents spent time with respondent $(\%)^{* *}$ & 54.6 & 41.4 \\
\hline Parents are very understanding (\%) & 67.4 & 67.5 \\
\hline $\begin{array}{l}\text { Quality of interaction with parents: parents spend/spent } \\
\text { time with } \mathrm{R} \text { and are/were understanding (\%)** }\end{array}$ & 43.2 & 33.9 \\
\hline
\end{tabular}

Note: Gender differences statistically significant, ${ }^{*} p<0.01,{ }^{* *} p<0.001$. 
Evidence from these interviews suggests that several students perceived that parents applied huge restrictions on their behaviour. Indeed, the first of the two quotes reported below suggests that strict parental controls on students' behaviour were perceived to have accelerated the shift towards sexual behaviour:

My parents are very strict with me. I have to take permission each time I go out of the house. If ever I get late, my father scolds me and sometimes even hits me for retuning late. I feared being hit...thereafter I started to bunk college and used to meet my boyfriend at his rented flat during the day time. Being at his place was fun and it gave us a lot more freedom and privacy than what we got standing near some shopping complex or in a restaurant. I wish I could tell my father that had he been not so strict, I would not have got so intimate with my boyfriend. (In-depth interview, undergraduate female student, SP University, age 18)

I know of many friends who tell their parent, 'I will commit suicide if you put so many restrictions on me'.... (In-depth interview, undergraduate male student, MS

University, age 19)

\section{Interaction and communication with peers}

Adolescence typically marks a shift in the spheres of influence from parents to peers (see, for example, National Research Council and Institute of Medicine, 2005, Selvan and Kurpad, 2004). Our findings confirm this suggestion but show, however, that peers played a far more important role in the lives of male than female students, and the shift from parents to peers as a source of support was also far more apparent among male than female students, as evident from Table 6.2 in which responses to a question relating to students' leading confidante on matters relating to boy-girl relationships and personal matters are presented. Findings suggest, for example, peers were the leading confidante for both male and female students. However, gender differences were apparent: among female students, many reported that they would confide in a parent as well as a friend (39\% and $44 \%$, respectively). In contrast, male students were far more likely to confide in a friend than a parent: two-thirds would confide in a friend, compared to one quarter who would confide in a parent. With regard to personal problems, both male and female students reported their parents as the leading confidante ( $45 \%$ and $56 \%$, respectively).

Questions were also posed to students about whether they had friends belonging to the same and opposite sex. While all students reported having same-sex friends, about half of female students (51\%) and three-fifths of male students (60\%) reported opposite sex friends, respectively. Students were also asked how often, in the three months preceding the interview, they had participated in various social activities with their peers ("Over the last 3 months, how many times have you done the following things?”). Activities are listed in Table 6.3 and findings reflect percentages who participated in each of these activities three or more times in the three months preceding the interview. Findings suggest that peers played an important role in the lives of students. Two-thirds of the female students and three-quarters of the male students reported frequent social interaction (three or more times in the three months preceding the interview) with these friends. Findings suggest that the most popular activity reported was eating out in restaurants and hotels, reported by two in five students ( $40 \%$ and $42 \%$ of female and 
Table 6.2:

Parents versus peers as confidantes on relationship matters and personal problems

\begin{tabular}{|l|c|c|} 
& $\begin{array}{c}\text { Female } \\
(\mathbf{N}=1808)\end{array}$ & $\begin{array}{c}\text { Male } \\
(\mathbf{N}=\mathbf{1 3 6 5})\end{array}$ \\
\hline $\begin{array}{l}\text { Most likely to confide about a relationship in (\%)** } \\
\text { Parents }\end{array}$ & 38.7 & 24.8 \\
$\quad$ Siblings/Relatives & 17.5 & 16.0 \\
Friends & 43.8 & 59.2 \\
Most likely to confide about personal problem (\%)** & & \\
$\quad$ Parents & 55.9 & 44.5 \\
Siblings/Relatives & 16.0 & 16.3 \\
Friends & 28.0 & 39.2 \\
\hline
\end{tabular}

Note: Gender differences statistically significant, ${ }^{*} p<0.01,{ }^{* *} p<0.001$

male students, respectively). While almost one in five male and female students reported going out on picnics (17\% of females and $19 \%$ of male students), other activities were more likely to be reported by male than female students: going to the movies ( $40 \%$ and $23 \%$ of male and female students, respectively); browsing the internet at cyber cafés (36\% and $20 \%$, respectively), health or sports clubs (18\% and $3 \%$, respectively) and attending late-night parties (13\% and $3 \%$, respectively). Indeed, male students were significantly more likely to report these activities than were their female counterparts: $55 \%$ of young women and $71 \%$ of male students reported engaging in social activities with their same-sex peers at least once in the last month.

In order to assess the extent of peer interaction, questions were also posed that related to peer interaction at the time of one particular celebration, namely, the Navratri festival that had taken place just three months prior to the interview. Notably, over one in four male students (27\%) and one in six female students (16\%) reported that they stayed out late almost daily during the nine nights of the festival. Gender differences were significant but findings highlight the extent to which both male and female students break-out of traditional role expectations at least during festival times.

Students were also asked about peer pressure (How much would you say you care about what peers think of you? Do you feel any pressure from your male friends to have a girlfriend/Do you feel any pressure from your female friends to have a boyfriend?). Peer pressure was evident. For example, almost half (46\%) of female students and over onethird (36\%) of male students reported that they cared very much about what their peers thought of them in general. About one-third of male students reported, moreover, that they experienced peer pressure to have a girlfriend (35\%), pressure that relatively few female students reported (10\%).

In-depth interviews also highlight the peer pressure experienced by students, particularly with regard to having a romantic relationship with the opposite-sex. For example: 


\section{Table 6.3:}

Peer interaction and pressure experienced by unmarried college students

\begin{tabular}{|c|c|c|}
\hline & $\begin{array}{l}\text { Female } \\
(\mathrm{N}=1808)\end{array}$ & $\begin{array}{c}\text { Male } \\
(\mathrm{N}=1365)\end{array}$ \\
\hline Have opposite sex friends (\%)** & 51.4 & 60.4 \\
\hline $\begin{array}{l}\text { Frequency of social interaction: } \% \text { students who reported } \\
\text { engaging in the following activities frequently }{ }^{1} \text { with peers } \\
\text { in the three months preceding the interview: }\end{array}$ & & \\
\hline Going to the cinema $(\%)^{* *}$ & 23.0 & 40.3 \\
\hline Going to a cyber café $(\%)^{* *}$ & 19.9 & 35.8 \\
\hline Eating out in restaurants/hotels (\%) & 39.6 & 42.1 \\
\hline Attending late-night parties (\%)** & 3.4 & 12.9 \\
\hline Going to health/sports club $(\%)^{* *}$ & 2.5 & 18.3 \\
\hline Going on picnics (\%) & 17.0 & 19.1 \\
\hline$\%$ reporting at least one of the above** & 55.4 & 70.7 \\
\hline $\begin{array}{l}\text { Stayed out later every night at festival time (Navratri) } \\
\text { than at other times }(\%)^{* *}\end{array}$ & 16.3 & 27.3 \\
\hline Cares very much about what peers think $(\%)^{* *}$ & 45.5 & 35.7 \\
\hline Experience peer pressure to have boy/girlfriend (\%)** & 9.7 & 35.2 \\
\hline
\end{tabular}

Note: Gender differences statistically significant, ${ }^{*} p<0.01,{ }^{* *} p<0.001 .{ }^{1}$ at least once a month

Friends influence us a lot because most people are not bold enough to think on their own. They get carried away by the influence of people around them. ... (In-depth interview, postgraduate female student, Gujarat University, age 22)

If boys don't have girlfriends they feel let down and depressed as these days having a girlfriend is a sort of status symbol. (Focus group discussion, undergraduate male students, SP University)

I am looked down upon by boys of my hostel because I don't have a girlfriend. Every evening when I return from college they ask me if I found one today. (In-depth interview, undergraduate male student, SP University, age 20)

Till I had a boyfriend, my friends used to tease me for not having one. (In-depth interview, postgraduate female student, MS University, age 20)

I am having sex with my girlfriend for fun and to be popular in my friends' circle. (In-depth interview, undergraduate male student, Gujarat University, age 17)

It's a shame for a post graduate boy if he has not had sex yet. It means that he is not experienced and did nothing in life. (Focus group discussion, postgraduate male students, MS University) 


\section{Opposite-sex romantic and sexual relations}

Findings of this study corroborate those of previous studies among college students concerning the prevalence of romantic and sexual relationships among male and female students. This chapter focuses on students' pre-marital sexual relationships with a partner belonging to the opposite sex, and the extent to which these relationships were unsafe.

\section{Romantic and sexual relations}

Although more than two-thirds of both male and female students agreed that it was acceptable for unmarried youth to have opposite sex romantic partners, fewer students reported that they had experienced such a relationship: 32\% of female students, and 54\% of male students. In total, moreover, $15 \%$ of female students and $37 \%$ of male students had ever experienced physical intimacy, and $5 \%$ of female students and $16 \%$ of male students reported engaging in sexual relations with an opposite sex partner.

A look at those who reported having a romantic partner reveals that physical intimacy was not experienced by all. Those reporting any kind of intimacy varied considerably from kissing on the lips, to touching private parts, to engaging in sexual relations. For example, among those male students who had a girlfriend, two-thirds had kissed the girlfriend on the lips, about half reported touching each other's private parts and onethird had engaged in sexual relations. Female students were less likely to report physical intimacy or sex with their boyfriend; even so, half had kissed the boyfriend on the lips, one-quarter reported touching each other's private parts and one in six had engaged in sexual relations with the boyfriend. We note the possibility that despite the anonymous reporting format, some students may have under-reported any sensitive behaviour.

Table 7.1:

Pre-marital romantic relations and physical intimacy including sex within romantic relationships

\begin{tabular}{|c|c|c|}
\hline & Female & Male \\
\hline Number of students & 1808 & 1365 \\
\hline Ever had boyfriend/girlfriend (\%)** & 31.5 & 53.9 \\
\hline Ever experienced any physical intimacy ${ }^{1}(\%)^{* *}$ & 15.4 & 36.7 \\
\hline Ever had sexual intercourse (\%)** & 5.2 & 16.4 \\
\hline Number of students reporting a boyfriend/girlfriend & 570 & 736 \\
\hline Ever kissed on lips $(\%)^{* *}$ & 47.4 & 65.8 \\
\hline Ever touched partner's private parts $(\%)^{* *}$ & 26.0 & 48.9 \\
\hline Ever had sexual intercourse (\%)** & 16.5 & 30.4 \\
\hline Ever experienced any physical intimacy ${ }^{\mathrm{a}}(\%)^{* *}$ & 47.8 & 67.4 \\
\hline
\end{tabular}

Note: Gender differences statistically significant, ${ }^{*} p<0.01,{ }^{* *} p<0.001 .{ }^{1}$ kissed on lips or touched private parts. 
Several female students discussed their reasons for not having a boyfriend, or not engaging in sexual relations with their boyfriends. Many reiterated the predominant attitude that if a girl has a boyfriend or has sex, her life is ruined, as discussed earlier. For example:

...we saw that girls who were into these matters (had boyfriends) had spoiled their lives as they did not do well in studies. ... So why get in all this mess of boyfriend? (In-depth interview, postgraduate female student, SP University, age 20)

Yes, certainly, kissing is very common and part of the relationship but I do not allow my boyfriend to kiss me. It's not that I don't love him or don't want him to kiss me but I know that if I allow him to kiss me, he would next want to touch me and then might want to have sex with me. I am very much in love with him. I want to marry him. But if I allow him to kiss me, he might lose interest in me and probably would not marry me. (In-depth interview, postgraduate female student, Gujarat University, age 22)

Questions were also posed on whether a peer had an opposite sex romantic partner and had engaged in sexual relations with that partner. Acknowledging that comparisons must be made cautiously, since each respondent may have more than one friend and that many respondents may be reporting romantic or sexual activity amongst the same peer group, comparisons are illustrative. They show that while 32 percent and 54 percent of female and male students, respectively, reported that they had an opposite sex romantic partner, many more -57 percent and 79 percent, respectively—reported that a peer had an opposite-sex romantic partner (not shown in tabular form). Gender differences in reports of pre-marital sex among peers were also wide. Among female students, while 5 percent reported pre-marital sex, 11 percent reported that at least one of their female friends had engaged in sexual relations; correspondingly, while just 16 percent of the male students reported pre-marital sex, 44 percent reported that a male friend had done so (not reported in tabular form). That pre-marital sex is well-known among the peer network is also evident from in-depth interviews. For example:

I have around 15 friends and I know that 12 of them have boyfriends and all of these 12 girls are physically involved with their boyfriends. ... I am so sure because they teach us how to make boyfriends stay in the relationship and they also teach us how to make sex more enjoyable. (In-depth interview, undergraduate female student, SP University, age 21)

\section{Sexual behaviours}

Among those who reported engaging in pre-marital sex in a romantic relationship with the opposite sex, questions were asked regarding the extent to which these relationships were risky or unwanted. Findings presented in Table 7.2 suggest that relations were overwhelmingly unsafe and for some, unwanted. Wide gender differences were evident.

Among sexually experienced male students, one in four had first experienced sex by the time they were 16, for two in three, the first sexual experience was unplanned, and for a 
small number (3\%), it was forced. Male students also reported risky recent experiences. For example, considerable proportions of sexually experienced male students reported that their last sexual encounter was casual (22\%), that they had experienced sex with multiple partners (40\%), or that they had ever engaged in paid or exchange sex (32\%).

Experiences of female students were quite different: the first sexual encounter typically occurred at an older age for female students (4\% before age 16) than for male students. Although about as many female as male students reported that the first sexual experience was unplanned (65\%), many more reported that it was forced (14\%). As far as overall experiences were concerned, partners were overwhelmingly a boyfriend, that is, a romantic partner (95\%), and multiple and exchange sexual encounters were rare ( $7 \%$ and $3 \%$, respectively).

\section{Table 7.2:}

Pre-marital sexual behaviours among sexually experienced unmarried college students in Gujarat, by sex of respondent

\begin{tabular}{|l|r|r|}
\hline Behaviours (Percent) & $\begin{array}{r}\text { Female } \\
(\mathbf{N}=\mathbf{9 4})\end{array}$ & $\begin{array}{r}\text { Male } \\
\text { (N=224) }\end{array}$ \\
\hline Circumstances of first sex & & \\
Age at first sex: 16 or younger** & 4.3 & 27.2 \\
First sex was unplanned & 64.9 & 66.5 \\
First sex was forced & 13.8 & 2.7 \\
Lifetime experiences & & \\
Last sexual partner** & & \\
$\quad$ Casual & 5.3 & 22.3 \\
$\quad$ Stable (Fiancé/Fiancée/Boyfriend/Girlfriend) & 94.7 & 77.7 \\
Multiple-partner sex** & 7.4 & 39.7 \\
Paid/exchange sex: Ever paid/received (money/gift) for sex** & 3.2 & 32.1 \\
Contraceptive use & & \\
Ever practised contraception & 90.4 & 85.7 \\
Method(s) ever used:\# & & \\
$\quad$ Condoms & 67.0 & 64.3 \\
$\quad$ Oral pills & 9.6 & 17.0 \\
$\quad$ Emergency contraceptive pills & 9.6 & 10.7 \\
$\quad$ Withdrawal & 48.9 & 48.2 \\
$\quad$ Others & 1.1 & 0.5 \\
Consistent contraceptive use & & \\
Consistent use of some contraception & 72.3 & 49.1 \\
Consistent use of condom & 34.0 & 30.3 \\
\hline
\end{tabular}

Note: Gender differences statistically significant, ${ }^{*} p<0.01,{ }^{* *} p<0.001$. \#multiple response 
In in-depth interviews, unwanted and paid sex experiences were extensively probed. The narratives of male students suggested that unwanted sex was rare, and many rationalised how sex was negotiated and consensual.

No, she did not stop me from having sex with her. Whatever I did was with her consent. I asked for her permission before I could kiss or touch her. I asked her for everything because I did not want her to blame me or say that I had used her and I had also told her in advance that I was not going to marry her. (In-depth interview, undergraduate male student, SP University, 20 years)

These days' boys and girls are very clear for what they want out of the relationship. See we are very young. We do not earn. We are dependent on parents then how can we think of marriage? In Gujarat, girls get married at a relatively early age, and they prefer marrying a boy settled abroad, so even they cannot make a commitment. That is why there is such good understanding among boys and girls. (Focus group discussion, postgraduate male students, MS University)

For the first time it is generally initiated by the boy but the girl too wants it. They may resist, but they do not stop us. (Focus group discussion, undergraduate male students, SP University)

In contrast, the narratives of several female students were more ambivalent and suggested that sex was not entirely consensual and that it involved an element of pressure, for example:

Persuasion-hundred percent the girl is persuaded to have sex. I can pledge on this because my friend told me that her boyfriend was going to marry her and that's why she agreed to his repeated request to have sex with him but after her boyfriend had sex with her, he started to fight with her and would find fault with everything she wore or did. Ultimately my friend got fed up and ended the relationship. After sometime through a common friend we got to know that boy's behaviour was intentional because he did not want to marry a girl who agreed to sex. (In-depth interview, postgraduate female student, SP University, age 23)

Well for me I would say it was neither under pressure nor had I given my consent for sex but my boyfriend insisted real hard. So it's like half consent. (In-depth interview, undergraduate female student, SP University, age 18)

I know boys will leave their girlfriend anyway. A year back, my friend refused to have sex with her boyfriend and the next day her boyfriend left her. The same girl was in a relationship again, this time she agreed to have sex, fearing rejection, but this man too left her saying that his old parents will not be able to withstand his inter-caste marriage. So that's why I say the boy's intention is just to have sex in $99 \%$ of the cases. I cannot live without my boyfriend. So I agree to him whenever he demands sex. I know his promises of marriage might be false but I am so attached to him that it is impossible for me to refuse him. (In-depth Interview, undergraduate female student, MS University, age 17) 
In addition, in the in-depth interviews, a number of students acknowledged that gifts and money were exchanged-from the male partner to the female partner. Male students clearly suggested the link between payment of gifts, and money and sex; narratives of female students were less clear and suggest that female students were more likely to interpret gifts as a symbol of commitment. For example:

Boys have to pay for sex anyhow. We give money to some prostitute or we buy gifts for girlfriends. Buying gift for girlfriend is still better because there we are sure that we are safe from AIDS and we have the privilege to spent time with her as much as we want. ... I have gifted so many things to my girlfriend or else she would not have had sex with me. I gave her bangles, a make-up kit, clothes, ear rings, shoes, rings, a necklace, $a$ watch and chocolates. She would take me shopping, select her gift and make me pay. At times I had to borrow money from my friends. (In-depth interview, postgraduate male student, SP University, age 24)

I know what to present my girlfriend then she cannot say no to sex. I give ornaments, tops, skirts and undergarments. I have followed this trend and none of my three girlfriends ever refused to have sex with me. (In-depth interview, postgraduate male student, Gujarat University, age 24)

My boyfriend comes from a very rich family. He would never let me pay for my educational material and books. Every month he would give me thousand to two thousand or even more if I needed for books and hostel fees. Since he is there I don't have to ask my parents to send extra money. He takes care of all my needs. My best friend... says that I have become like a prostitute as he gives me money but I don't think so because he is not paying to have sex with me...seven months after I accepted his proposal, he took me to his farm house and had sex with me. I just could not refuse him. (In-depth interview, undergraduate female student, SP University, age 18)

Sexually experienced students were also asked about their contraceptive practices. The overwhelming majority—90 percent and 86 percent of female and male students, respectively, reported that they had ever used a method of contraception. The two leading methods were condoms (reported by about two-thirds of all students), and withdrawal (reported by about half); no gender differences were evident.

Consistent contraceptive use was less likely to be reported—by 72 percent of female students and 49 percent of male students. Consistent condom use was rare, reported by just one-third of female and male students alike. In the course of in-depth interviews, students corroborated the fact that relations were sometimes unsafe. Several reported that the spontaneous nature of sex made it impossible to have protected sex. For example:

If sex were planned, I would always use a condom but the problem is that I am a local student and my girlfriend is also a local student and we can rarely plan sex. Though I want to use a condom, I cannot as I do not have one with me when I need it, so most of the time I manage by ejaculating outside. (In-depth interview, postgraduate male student, Gujarat University, age 22) 
I have had sex with all my five girlfriends. The first time I had sex with each of them I did not use a condom because the first time was always unplanned and moreover I know that a girl cannot get pregnant in her first sexual contact. In subsequent experiences, I have used Durex condoms. (In-depth interview, postgraduate male student, SP University, age 23)

Several narratives of female students suggested, moreover, that females did not participate in condom-related decision making, leaving the decision on condom use to the partner. For example:

We could have had sex without condoms as I trust him. For sure he was not involved with any other girl than me so there was no question of getting AIDS but my boyfriend made sure we used protection every time we had sex because he did not want me to get pregnant and invite trouble for both of us. (In-depth interview, undergraduate female student, MS University, age 19)

\section{Factors associated with pre-marital sex and consistent condom use}

Earlier sections discussed a number of individual-, family- and peer-level factors characterising students' lives, some of which have been observed in studies elsewhere to play a role in influencing whether or not youth engage in pre-marital sex, and whether these sexual relations are safe. In this section, we assess associations, using logistic regression analysis, between several factors (as listed in Table 7.3) and three measures of sexual behaviour: experience of any physical intimacy; and experience of sexual activity among all students on the one hand; and consistent condom use, among sexually experienced male students (small numbers preclude this analysis for females), on the other. Table 7.3 presents findings, by way of odd ratios associated with each indicator.

Individual-level factors were associated with both physical intimacy and sexual experience, but the strength and direction of these associations varied with the outcome indicator. Gender differences were also apparent, with fewer significant associations observed for female than male students.

With regard to both physical intimacy and sexual experience, two individual-level indicators —age and exposure to pornographic films, were significantly and positively associated with sexual experience among both female and male students. Additionally, findings suggest that those in the Arts faculty were more likely-significantly and consistently among male students, and mildly and inconsistently among female studentsthan others to have experienced sexual relations. Also significant among male but not female students was alcohol consumption: male students reporting alcohol consumption were significantly more likely than others to have experienced physical intimacy and sex. Other factors-such as negotiation skills and regular class attendance-were unrelated to both physical intimacy and sexual experience among both male and female students.

In the case of parental factors, correlates differ for male and female students. Among male students, findings show that maternal education was clearly a deterrent to physical intimacy and, in particular, sexual experience; among female students, no such association 
was evident. It is notable that neither residence away from parents nor parental strictness nor quality of interaction was related to physical intimacy, or with sexual experience among both male and female students.

Peer-level factors were also significant. Frequent social interaction with peers was positively associated with both physical intimacy and sexual experience among both male and female students. Additional peer-level associations were also observed for male students: those staying out late at festival times (navratri), those reporting peer pressure to have a girlfriend, had significantly elevated odds of experiencing both physical intimacy and sex. Indeed, in-depth interviews with male students corroborated that festival times offered opportunities for sexual relations that were not available at other times, for example:

This Navratri was fun. I was with my girlfriend for three nights. We had planned in advance that we would be meeting during Navratri. We went out for 'Garba' with our respective neighbours to the Garba ground in traditional dresses and join the dancing. Our parents did not know about this. From the 'Garba' ground I took her to my uncle's vacant house. My girlfriend and I used to be together till three at night. We had sex all the three days then by 3 AM I used to drop her at the Garba ground so that she could join her neighbours there and return home along with them. There are so many people, if you disappear from the ground hardly anyone will come to know about it. Parents are very liberal during these days, they give permission easily, while on the other days my girlfriend had to return home latest by 7 PM. (In-depth Interview, undergraduate male student, SP University, 20 years)

During Navratri, we had sex every night as it was easy for her to come out for the night but I had to shell out money for the hostel room during that time because the room was in great demand. I had to pay Rs 200 for two hours. Well, this is the trend with many boys during Navratri or New Year's Eve, students give their room on hourly rent. (In-depth interview, undergraduate male student, SP University, 21 years)

Fewer factors were significantly associated with consistent condom use among sexually experienced male students. Maternal education was consistently and positively associated with consistent condom use and was, by far, the most significant correlate. Also significant, but inversely associated, was age, suggesting perhaps that condom use tended to become irregular among those in longer-standing relationships. Of interest was the finding, moreover, that male students who reported regular class attendance had significantly elevated odds of consistent condom use and that those in the Science stream were significantly more likely to report consistent condom use than those in the Commerce stream. Also notable is that neither parental strictness nor the quality of parental interaction was associated with consistent condom use. Finally, not a single peerlevel factor was associated with whether or not consistent condom use was practised. 


\section{Table 7.3}

Odd ratios from logistic regression analyses assessing the likelihood that students had ever experienced physical intimacy, sexual relations and that sexually experienced students had practised consistent condom use, by selected characteristics

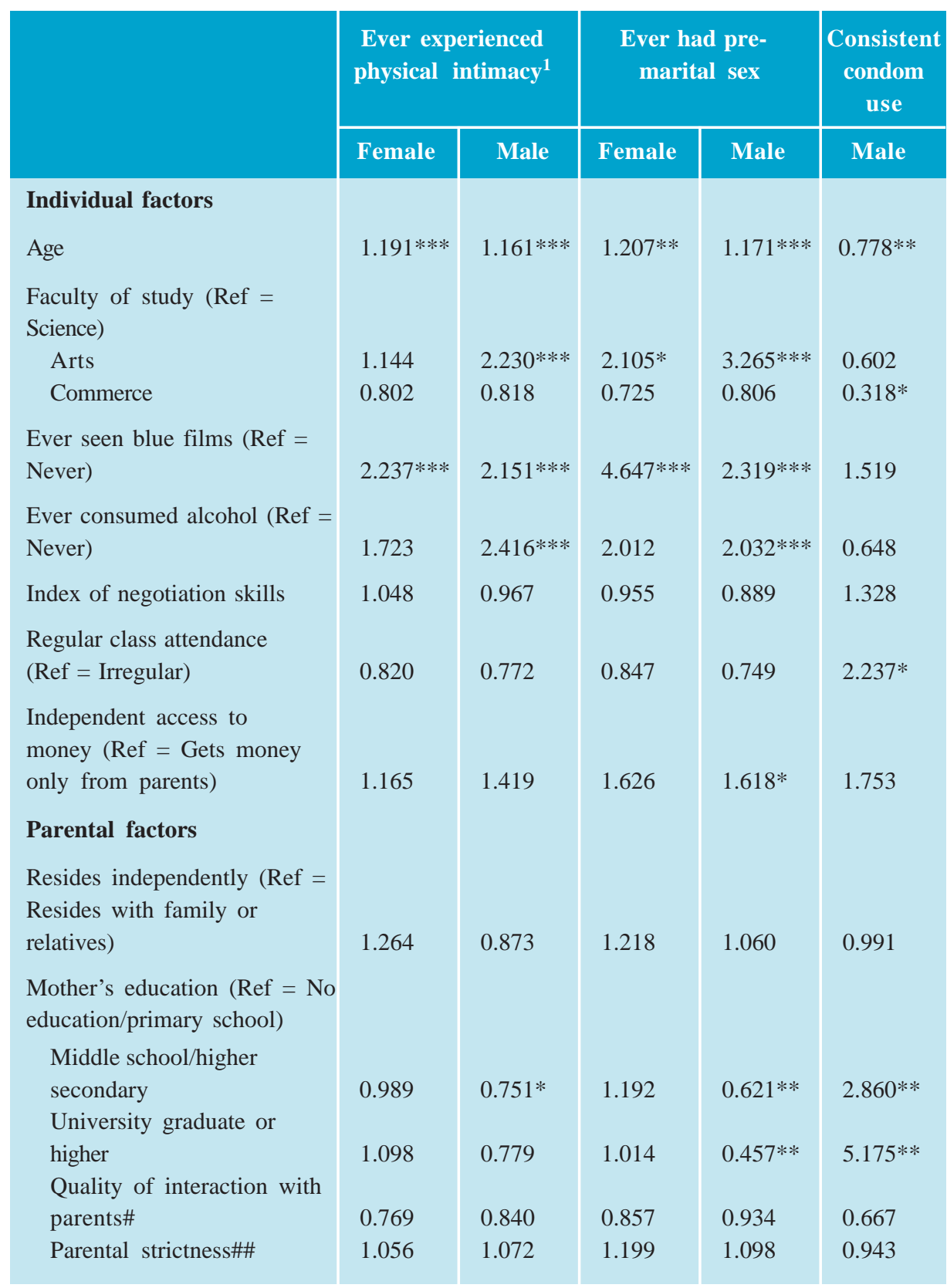


Table 7.3 (Cont'd)

\begin{tabular}{|c|c|c|c|c|c|}
\hline & \multicolumn{2}{|c|}{$\begin{array}{l}\text { Ever experienced } \\
\text { physical intimacy }^{1}\end{array}$} & \multicolumn{2}{|c|}{$\begin{array}{l}\text { Ever had pre- } \\
\text { marital sex }\end{array}$} & \multirow{2}{*}{$\begin{array}{c}\begin{array}{c}\text { Consistent } \\
\text { condom } \\
\text { use }\end{array} \\
\text { Male }\end{array}$} \\
\hline & Female & Male & Female & Male & \\
\hline Peer factors & & & & & \\
\hline $\begin{array}{l}\text { Frequent social interaction } \\
\text { (in last } 3 \text { months) (Ref = } \\
\text { Infrequent) }\end{array}$ & $1.774 * *$ & $1.577 * *$ & $1.939 * *$ & $1.718^{* *}$ & 1.080 \\
\hline $\begin{array}{l}\text { Awareness of sexual and } \\
\text { reproductive health matters } \\
\text { (of } 6 \text { matters) }\end{array}$ & - & - & - & - & 0.987 \\
\hline $\begin{array}{l}\text { Perceives peer pressure to } \\
\text { have boy/girl friend (Ref = } \\
\text { Does not perceive peer } \\
\text { pressure) }\end{array}$ & 1.394 & $1.737^{* * *}$ & 1.487 & $1.405 *$ & 1.711 \\
\hline $\begin{array}{l}\text { Confide in friends about } \\
\text { personal problems (Ref }= \\
\text { Does not confide in friends) }\end{array}$ & $2.424 * * *$ & 1.224 & $1.804 *$ & 1.001 & 0.845 \\
\hline $\begin{array}{l}\text { Frequent socialisation } \\
\text { during Navratri (Ref = } \\
\text { Infrequent socialisation) }\end{array}$ & 1.326 & $1.860 * * *$ & 1.151 & $1.518 *$ & 1.413 \\
\hline Constant & $0.002 * * *$ & $0.007 * * *$ & $0.000 * * *$ & $0.002 * * *$ & 17.991 \\
\hline $\mathrm{N}$ & 1804 & 1363 & 1804 & 1363 & 224 \\
\hline$-2 L L$ & 1398 & 1554 & 633 & 1035 & 233 \\
\hline $\mathrm{R}$ square & 0.140 & 0.219 & 0.168 & 0.212 & 0.263 \\
\hline
\end{tabular}

Note: ${ }^{*} p<0.05,{ }^{* *} p<0.01,{ }^{* * *} p<0.001 .{ }^{1}$ kissed on lips or touched private parts \# Parents were both very understanding and spent a lot of time with respondent. \#\# index ranging from 0 (not strict on all four matters) to 4 (strict on all four matters), Ref = reference category

In summary, findings suggest that even after controlling a host of factors, a range of individual, parent-level and peer factors are strongly associated with whether or not students have experienced physical intimacy or engaged in sexual relations. In contrast, relatively few factors are observed to influence consistent condom use among male students. Indeed, it is notable that neither socialisation patterns, nor relations with parents, nor peer influences could explain consistent condom use among male students. 


\section{Unintended pregnancy and abortion}

Unintended pregnancy and abortion are matters about which it is very difficult to obtain reliable information, especially from the unmarried. Even so, the anonymous format gave students an opportunity to report the experience of unintended pregnancies. Findings, presented in Table 8.1 reveal that as many as 9 percent of all sexually experienced female students (and 0.4 percent of the entire sample) had experienced an unintended pregnancy. A somewhat larger proportion— 17 percent—of sexually experienced male students reported that they had made a girl pregnant ( 3 percent of the entire male sample) and 4 percent reported that they had done so more than once. The outcome of most unintended pregnancies was abortion, although a few reported an ongoing pregnancy (Data not shown in tabular form).

\section{Table 8.1:}

Unintended pregnancy experiences reported by sexually experienced male and female students

\begin{tabular}{|l|c|c|}
\hline Unintended pregnancy & $\begin{array}{c}\text { Female } \\
(\mathbf{N = 9 4 )}\end{array}$ & $\begin{array}{c}\text { Male } \\
(\mathbf{N}=\mathbf{2 2 4})\end{array}$ \\
\hline Ever been/made a partner pregnant (\%) & 8.5 & 16.5 \\
\hline Experience one pregnancy (\%) & 8.5 & 12.9 \\
\hline Experience more than one pregnancy (\%) & 0.0 & 3.6 \\
\hline
\end{tabular}

Information obtained in the course of focus group discussions and especially in-depth interviews corroborate the finding that pregnancy and abortion were not unknown among students. Female students reported, for example, familiarity with the practice of abortion, including medical abortion, and several described experiences of their friends, and sometimes themselves. Abortion was, for many, an acceptable practice and student narratives referred to the ease with which medical abortion could be obtained:

Many of our friends say that it is OK if they are having sex and if they get pregnant they will take pills to drop the baby. (Focus group discussion, undergraduate female students, MS University)

Several female students reported their own experiences; many had undergone medical abortion:

For the first six months when we started to have sex we didn't use anything-not even pills-but then a disaster happened. I got pregnant. I had to get an abortion. No doubt my boyfriend was with me throughout but the gynaecologist gave me some pills for abortion. Believe me, it was very painful. I will never again go for abortion. Since 
then we regularly use condoms. Neither of us enjoys this but we use condoms to avoid my getting pregnant again. (In-depth interview, undergraduate female student, SP University, age 18)

One morning I felt very nauseated and weak. I had also not got my periods. I told my boyfriend about my sickness and he told his landlord about the problem. His landlord knew about our relationship because he used to see me many times at my boyfriend's place. He took us to a leading gynaecologist. I wore a sari and many bangles and we pretended to be recently married at the clinic. We also gave a wrong name at the clinic. The doctor gave me two pills for Rs 1500. After a day I was in terrible pain and the bleeding was heavy but it was ok since the problem was solved. Since then we know the name of the tablets, we have bought them twice after this incident from the chemist nearby. (In-depth interview, undergraduate female student, SP University, age 20)

Several male reported the availability of a supportive network of friends who could be relied on to facilitate the abortion, by way of locating an appropriate provider or raising the required resources. Qualitative data suggests that several boys were well prepared to pay in case their girlfriends needed to abort the pregnancy. For example:

My friends are very supportive. They said there is no need to worry and that I should just enjoy sex. They said that if ever anything happened to my girlfriend they will find a way for abortion. They have contact with a gynaecologist who is very supportive. In the past, three of my friends had got their girlfriends' abortions done at his clinic. This doctor told us that getting abortions done is illegal in our country but he understands the plight of students, so he will charge less, around Rs 5000 and will keep the secret just to himself. So our group does not use condoms. We have a reserve of Rs 5000 for emergency, anyone might need it. (In-depth interview, undergraduate male student, MS University, age 21)

Well I could say around $80 \%$ of the time I use a condom. Sometimes when I do not feel like using it like if I don't have it with me or I am not in the mood to wear it, I take the risk of pregnancy because I know that if my girlfriend gets pregnant, my expert friends are there to arrange for an abortion. (In-depth interview, undergraduate male student, Gujarat University, age 18)

Experiences of local gynaecologists and pharmacists were also sought through in-depth interviews. These interviews corroborated the suggestion that abortion was not uncommon among college students. Indeed, several providers reported that college students were among their leading clients for abortion. For example:

Most of the time my cases are college girls, I would say 80 percent of the time it's a college-going girl, the rest 20 percent are school girls from classes 10, 11 or 12 who come for abortion. College girls come with their friends-usually her boyfriend-while the younger ones come with their mother or elder sister. (Key-informant interview, gynaecologist, practising around SP University) 
I usually get 2-3 cases of college- going students for MTP a month. Some five/six years back I used to receive 8-9 cases of abortion a month from this age group but the knowledge of contraception and the availability of mifepristone and misoprostol has reduced such cases. (Key-informant interview, gynaecologist, practising around SP University)

It's my observation that 90 percent of the girls who come to abort, come to the clinic after taking ayurvedic tablets to commence menstruation without any results. They would have also tried taking chloroquine (anti-malaria tablets), eating raw papaya or drinking a decoction of hot water and black pepper to start menstruation. I feel coming to a gynaecologist is the last option for them. (Key-informant interview, gynaecologist, practising around MS University)

Twenty five percent of my abortion clients are school-going girls, say from class 9-12, 50 percent are college-going girls and the rest are married women. (Key-informant interview, gynaecologist, practising around MS University)

I know I am not allowed to sell mifepristone and misoprostol without a doctor's prescription but if I don't sell, a neighbouring chemist will sell. And anyway, the doctor is going to give the same drug. I inform all users about the side effects and complications that could arise after using this drug. There is a huge commission on this drug, I don't think its over-the-counter sale can ever be stopped. (Key-informant interview, pharmacologist, SP University)

One gynaecologist also countered the perception that the incidence of abortion increases following festival time, notably navratri. This key informant confirmed that unmarried college females sought abortion from her regularly, but argued that abortion-seeking was not seasonal:

I get around two to three cases of abortion from unmarried college-going girls every month and the figure remains more or less the same throughout the year. The media must be reporting exaggerated data for increase in abortion cases during or after festival time. None of my friends practicing in and around the city have told me about an increase in cases nor have I witnessed any such increase. (Key-Informant Interview, Gynaecologist, SP University) 


\section{Summing up and recommendations}

\section{Summing up}

This study, exploring the extent of and factors associated with pre-marital sexual relations among unmarried college students in Gujarat, builds on previous research and makes several new and important contributions to understanding the levels and patterns of premarital relationships among college-going students in India. The study included a survey of 3,173 female and male students of three universities in Gujarat, as well as focus group discussions and in-depth interviews with students and key-informant interviews with parents, teachers and health-care providers.

Findings suggest that attitudes to pre-marital sex were typically gendered, with students far more likely to condone it among men than women, putting young women who engaged in sexual relations in an extremely vulnerable situation. At the same time, awareness of sexual and reproductive matters was relatively limited and fewer than half of all students had been exposed to sexuality education in school or college. Again, female students were more vulnerable and considerably more poorly informed than male students about, for example, HIV and the protective role of condoms; however, neither group was well informed about the fact that a woman can become pregnant the first time she has sex, or that condoms and oral pills were effective methods of contraception.

Against this backdrop of limited awareness and gendered attitudes towards pre-marital sex, findings stress that the development of pre-marital romantic relationships are fairly widespread among college students. Overall, over half of male students reported that they had a girlfriend and about one-third of female students reported that they had a boyfriend. Sexual relations were reported by considerably fewer-16 percent and 5 percent of male and female students, respectively_levels that fall within the broad range reported in other studies conducted in India (Jejeebhoy and Sebastian, 2004; Abraham and Kumar, 1999; Alexander et al., 2006).

Large proportions of the sexually experienced reported consistent contraceptive practicealmost three-quarters of female students had experienced unintended pregnancy and about one in six male students. About one-third of sexually active students reported consistent condom use, a considerably larger proportion than has been reported in other studies (see Jejeebhoy and Sebastian, 2004). Even so, it is clear that sexual relations remained unsafe for many, with 7 percent and 40 percent of sexually experienced female and male students reporting multiple partner relations and about two-thirds reporting unprotected sex. Also, close to one-tenth of sexually experienced female students reported unintended pregnancy, and one in seven sexually experienced male students reported that they had made a girl pregnant, further underscoring findings of unsafe sexual practices. Finally, a disturbing minority—one in seven—of sexually experienced females reported a forced sexual encounter. 
In addition, our study adds to the limited body of research on the associations between individual, peer and family factors and sexual experience, on the one hand, and safe sex practices among the sexually experienced, on the other, among college-going youth. Our findings, like those of previous research, suggest that associations vary by outcome measure as well as for male compared to female students. While age, exposure to pornographic films, frequent peer contact were significantly correlated with physical intimacy and sexual experience among both male and female students, several more were also significant among male students: alcohol consumption, independent access to money and experience of peer pressure were significantly associated with the likelihood that male students engaged in sexual relations. On the other hand, maternal education was consistently and inversely associated with experiences of physical intimacy and sex among them. Interestingly, among both male and female students, neither independent living arrangements nor strictness of upbringing were associated with physical intimacy or sexual experience.

Fewer factors were associated with safe pre-marital sex among sexually experienced male student. Age appeared to inhibit consistent condom use, while mother's education and regular class attendance were associated with significantly higher levels of consistent condom use. Peer factors and such parental factors as co-residence and strictness were unrelated with safe sex.

A disturbing indicator of the extent of unsafe sex was student experience of abortion. While numbers are small and findings should be interpreted cautiously, findings suggest that about one in ten sexually active female students reported the experience of unintended pregnancy; about one in six male students reported that they had ever made a girl pregnant. All those reporting unintended pregnancy reported that they had undergone abortion, a finding corroborated by a number of providers interviewed as part of the study.

\section{Limitations}

Potential limitations of this study must be acknowledged. First, we acknowledge that because the study was classroom-based, we were only able to obtain the perspectives of those who had attended class on the day the survey was fielded; several students, mostly male, who combined work with college, or who were not in the classroom (in the college canteen for example) were excluded and it is possible that their experiences were different from those who attended class. Second, young people in our sample may have underreported their romantic, physical and sexual experiences-a limitation observed in most studies of this nature. As others have noted, powerful social norms prohibit premarital friendships with the opposite sex, whether they are platonic, romantic or sexual. In such a setting, relationships are usually carried on secretly, and youth—particularly young females, who have more to lose than young males-may be unwilling to disclose them (see, for example, Alexander et al., 2006). This hesitation to disclose personal details was addressed, to some extent, through the use of the self-reporting format and the opportunity to report sexual behaviour anonymously. Even so, we cannot rule out the underreporting of pre-marital experiences and possible measurement error, particularly among female students. 
A third potential limitation is the cross-sectional nature of our study and the resulting inability to infer causation. Our study findings are suggestive, but cannot be interpreted as evidence of the determinants of sexual relations.

\section{Recommendations}

This study has important programmatic and policy implications. Romantic partnerships and physical intimacy were reported by considerable proportions of male and female students; pre-marital sex among notable minorities and unsafe sex, and even the experience of abortion characterised many sexual relationships among young students. At the same time, awareness of sexual and reproductive matters was limited and attitudes to premarital sex typically gendered. In this context, it is critical that policies and programmes for students work towards ensuring that in forming partnerships, youth are fully informed and equipped to make safe choices. Our findings suggest at least four areas for intervention.

For one, evidence suggests that students are not well informed about matters relating to sex and relationships, and leading sources of information are the media and peers. Few, moreover, had been exposed to sex education. These kinds of findings call for sex education among students, both while they are in school, as in the school-based AIDS education programme, and while in college. It is important that colleges in Gujarat organise sex education programmes that inform students not only about HIV/AIDS but also about relationships and the need for gender equitable attitudes and relationships.

Second, findings have underscored the links between peer contact and sexual experience. The narratives of many students suggested, moreover, that peers were a source of information and support regarding both relationships and accessing abortion services in case of unintended pregnancy. At the same time, peer pressure to engage in sexual relations was apparent and may have resulted in students engaging in romantic and sexual relations without being fully prepared. Leadership development programmes are needed at the college level that enable youth to counter adverse peer pressures; at the same time, peer-led programmes at the college level may be an important and acceptable way whereby students may obtain information, contraceptive supplies and counselling referrals. College-level programmes that breakdown inhibitions about condom use, lead students to associate condom use with 'cool' behaviour and enable youth to access supplies from a trusted source—such as a peer leader—must be considered.

Third, evidence calls for programmes that address parents and encourage parent-child connections. Programmes are needed that break down parental inhibitions and encourage communication from an early age, including in age-appropriate ways, on sexual matters while their children are still young. Parents themselves may not be fully aware of sexual and reproductive matters and efforts are needed to raise their levels of awareness and support them. Parents must be informed, for example, that strict controls on children's behaviour and authoritarian parenting styles may prevent sexual relations among them but do not ensure that safe sex is practised; they also must be made aware that students who co-reside with their parents are no less likely than those who reside independently to engage in sexual relations. Parent-teacher forums may be a good way of imparting 
awareness and parenting skills to parents of school- and college-going youth. Other methods may include, for example, school assignments that require parents and children to participate in completing case studies and quizzes related to sexual and reproductive health topics; seminars, lectures and discussions may be held for students' parents, in which their communication skills are sharpened and awareness of adolescent reproductive health matters are discussed. Parent-teacher meetings may, likewise, provide opportunities for developing communication and parenting skills of parents; schools may develop forums for parent-son/daughter interaction and use these forums to discuss sexual and reproductive matters. Finally, selected parents may be identified as peer educators and provide support to others in their respective communities.

Finally, evidence suggesting that abortion is experienced by sizeable minorities of students calls for appropriate health services for college students. Our findings show that students hold misconceptions, seek and obtain over-the-counter remedies for abortion, and solicit the services of a specialist only when other options fail. Questions arise regarding the reach of health services amongst students, both for contraception and abortion services, and the need for linkages between the health sector and the university setting. 


\section{References}

Abraham, L and A.K. Kumar. 1999. "Sexual Experiences and Their Correlates among College Students in Mumbai City, India,” International Family Planning Perspectives, 25(3): 139-146.

Abraham, L. 2002. "Bhai-Behen, True love, Time-pass-friendship and sexual partnerships among b in an Indian Metropolis," Culture, Health and Sexuality, 4(3): 337-353.

Alexander, M. L., S. Garda, S. Kanade et al. 2006. Formation of partnerships among young women and men in Pune district, Maharashtra. New Delhi: Population Council.

Awasthi, S. and V.K. Pande. 1998. Sexual behaviour patterns and knowledge of sexually transmitted disease in adolescent boys in urban slums of Lucknow. Indian paediatrics, 35 (11): 1105-9.

Bearman, P. S. and H. Brückner. 1999. "Peer Effects on Adolescent Girls' Sexual Debut and Pregnancy: An analysis of a national sample of adolescent girls,” in Peer Potential: Making the Most of How Teens Influence Each Other. National Campaign to Prevent Teen Pregnancy. Washington, D.C.

Cleland J. 2001. "Illustrative questionnaire for interview-survey with young people," in Asking Young People About Sexual and Reproductive Behaviours: Illustrative Core Instruments, eds. J. Cleland, R. Ingham and N. Stone. Geneva: World Health Organisation, pp. 5-16.

Collumbien, M., B. Das and N. Bohidar. 2008. "Early sexual experience of males in Orissa: Context, partners and differentials,” in Reproductive Health In India: New Evidence, eds. Michael A. Koenig, Shireen Jejeebhoy, John C.Cleland and Bela Ganatra. Delhi: Rawat Publications.

Gujarat Behavioural Surveillance Survey. 2000. "Summary Report: Behavioural Surveillance Survey in Gujarat, India,” A study implemented by ORG Centre for Social Research, under the guidance of Gujarat State AIDS Control Society, with technical assistance from Family Health International.

Gujarat State AIDS Control Society. 2006. Annual Report up to 31 ${ }^{\text {st }}$ March 2006. http://www.gujhealth.gov.in/health_programmes/pdf/AIDS/Annual\%20Report.pdf. Ahmedabad: Gujarat State AIDS Control Society.

International Institute for Population Sciences (IIPS) and ORC-Macro. 2007. National Family Health Survey (NFHS-3), 2005-06, India: volume I. Mumbai: IIPS. 
International Institute for Population Sciences (IIPS) and Population Council. 2008. Youth in India: Situations and Needs 2006-07, Maharashtra. Mumbai: IIPS.

Jejeebhoy, S. J. 2000. Adolescents sexual and reproductive behaviour: A review of evidence from India in Women's Reproductive Health in India, eds.

R. Ramasubban and S. J. Jejeebhoy. Jaipur: Rawat Publications, pp. 40-101.

Jejeebhoy, S.J. and M.P Sebastian. 2004. "Actions that protect: Promoting sexual and reproductive health and choice among young people in India," in Looking Back, Looking Forward: A Profile of Sexual and Reproductive Health in India, ed. S.J. Jejeebhoy. Jaipur: Rawat Publications, pp. 138-68.

Karim, A., R. J. Magnani., G.T Morgan, et al. 2003. "Reproductive health risk and protective factors among unmarried youth in Ghana," International Family Planning Perspectives, 29(1): 14-24.

Kirby, D. 2001. "Understanding what works and what doesn't in reducing adolescent sexual risk-taking,” Family Planning Perspectives, 33(6): 276-281

Mehra, S., R. Savithri and L. Coutinho. 2002. "Sexual behaviour among unmarried adolescents in Delhi, India: Opportunities despite parental controls," paper presented at the IUSSP Regional Population Conference, Bangkok, June.

Mohammadi, M., K. Mohammad., F, Farahani, et al. 2006. "Reproductive knowledge, attitudes and behavior among adolescent males in Tehran, Iran,” International Family Planning Perspectives, 32(1):35-44.

National Research Council and Institute of Medicine. 2005. Growing up global: The changing transitions to adulthood in developing countries. Washington, DC: National Academic Press.

Office of the Registrar General and Census Commissioner, India (RGI). 2001a. Population Attending Educational Institution by Age, Sex and Type of Educational Institution, Table C-10. New Delhi: Office of the Registrar General and Census Commissioner.

2001b. Primary Census Abstract, total Population: Table A-5, Series 1. New Delhi: Office of the Registrar General and Census Commissioner.

Patel, V. and G. Andrew. 2001. "Gender, sexual abuse and risk behaviours: A study of school based adolescents in Goa," National Medical Journal of India, 14:263-67.

Sachdev, P. 1998. "Sex on campus—A preliminary study of knowledge, attitudes, and behavior of university students in Delhi, India," Journal of Biosocial Science, 30(1): 95-105. 
Selvan, M. and A. Kurpad. 2004. "Primary prevention: Why focus on children \& young adolescents?” Review Article. Indian Journal of Medical Research, 120: 511-518.

Shekhar, M., S. Ghosh and P. Panda. 2007. "Exploring Safe Sex Awareness and Sexual Experiences of Adolescents in Patna”, Economic and Political Weekly, 42(48): 48-55.

Sodhi, G., M. Verma and P. J. Pelto. 2008. "Seeking gratification: a study of sexual behaviour patterns of adolescents in an urban slum," in Reproductive health in India: New evidence, eds. Michael A. Koenig, Shireen Jejeebhoy, John C.Cleland and Bela Ganatra. Delhi: Rawat Publications.

University Grants Commission. nd. Annual report 2005-2006, New Delhi: University Grants Commission. 


\section{Acknowledgments}

This study would not have been possible without the support and encouragement of a number of people and organisations. I would like to thank the Vice Chancellors, Registrars, College Principals and class teachers of Gujarat University (Ahmedabad), Maharaja Sayajirao University (Vadodara) and Sardar Patel University (Vallabh Vidyanagar, Anand) for permitting me to undertake this sensitive but relevant research. In particular, I want to express my gratitude to Professor Gaurang Jani, Department of Sociology, Gujarat University, Dr. D.M. Saxena, former Additional Director, Gujarat AIDS Control Society, Dr. S.K. Dixit, Dean-Agriculture and Information Technology, Anand Agricultural University, Anand for their guidance and support through the project. I would also like to place on record my appreciation to Dr. Vinit Sharma, Technical Adviser-Maternal Health, SRO for South and West Asia, UNFPA, Kathmandu, Nepal, for his time and patience in mentoring me. Special thanks to Mr. Satheesh Chandra (Assistant Director, SOMA) for providing useful inputs from inception to completion of the survey.

Finally I want to thank all the participants of the survey who gave their time and, above all, shared their valuable personal experiences on the various facets of the survey. I am especially grateful to the parents, teachers, health care providers and pharmacists who have given valuable information and their perspectives that enriched the survey findings.

I would like to thank Shireen Jejeebhoy, K.G. Santhya, Shveta Kalyanwala, Rajib Acharya, A.J. Francis Zavier and Komal Saxena at the Population Council for their guidance throughout the study and on previous versions of this report. Francis Zavier painstakingly reviewed tabulations and supported the statistical analysis and his contribution is much appreciated. I am also grateful to Dr. Pertti J. Pelto and Dr. Usha Ram for reviewing the report and to Anindita Majumdar for editing the manuscript. 
